\title{
Human high-density lipoprotein particles prevent activation of the JNK pathway induced by human oxidised low-density lipoprotein particles in pancreatic beta cells
}

\author{
A. Abderrahmani - G. Niederhauser • D. Favre • \\ S. Abdelli • M. Ferdaoussi • J. Y. Yang • R. Regazzi • \\ C. Widmann • G. Waeber
}

Received: 30 October 2006 / Accepted: 15 January 2007 / Published online: 17 April 2007

(C) Springer-Verlag 2007

\begin{abstract}
Aims/hypothesis We explored the potential adverse effects of pro-atherogenic oxidised LDL-cholesterol particles on beta cell function.

Materials and methods Isolated human and rat islets and different insulin-secreting cell lines were incubated with human oxidised LDL with or without HDL particles. The insulin level was monitored by ELISA, real-time PCR and a rat insulin promoter construct linked to luciferase gene reporter. Cell apoptosis was determined by scoring cells displaying pycnotic nuclei.

Results Prolonged incubation with human oxidised LDL particles led to a reduction in preproinsulin expression levels, whereas the insulin level was preserved in the presence of native LDL-cholesterol. The loss of insulin production occurred at the transcriptional levels and was
\end{abstract}

Electronic supplementary material The online version of this article (doi:10.1007/s00125-007-0642-z) contains supplementary material, which is available to authorised users.

A. Abderrahmani $\cdot$ G. Niederhauser $\cdot$ D. Favre $\cdot$ S. Abdelli $\cdot$

M. Ferdaoussi $\cdot$ G. Waeber

Service of Internal Medicine, CHUV-Hospital,

Lausanne, Switzerland

A. Abderrahmani $(\bowtie) \cdot$ G. Niederhauser $\cdot$ D. Favre $\cdot$ S. Abdelli

M. Ferdaoussi $\cdot$ J. Y. Yang $\cdot$ R. Regazzi $\cdot$ C. Widmann $\cdot$ G. Waeber

Department of Cellular Biology and Morphology,

University of Lausanne,

Rue du Bugnon 9,

1005 Lausanne, Switzerland

e-mail: Amar.Abderrahmani@unil.ch

J. Y. Yang $\cdot$ C. Widmann

Department of Physiology, University of Lausanne,

Lausanne, Switzerland associated with an increase in activator protein-1 transcriptional activity. The rise in activator protein-1 activity resulted from activation of c-Jun N-terminal kinases (JNK, now known as mitogen-activated protein kinase 8 [MAPK8]) due to a subsequent decrease in islet-brain 1 (IB1; now known as MAPK8 interacting protein 1) levels. Consistent with the pro-apoptotic role of the JNK pathway, oxidised LDL also induced a twofold increase in the rate of beta cell apoptosis. Treatment of the cells with JNK inhibitor peptides or HDL countered the effects mediated by oxidised LDL.

Conclusions/interpretation These data provide strong evidence that oxidised LDL particles exert deleterious effects in the progression of beta cell failure in diabetes and that these effects can be countered by HDL particles.

Keywords Apoptosis · Diabetes · HDL · Insulin · JNK pathway - MAPK $\cdot$ Oxidised LDL $\cdot$ Pancreatic beta cells

$\begin{array}{ll}\text { Abbreviations } \\ \text { AP1 } & \text { activator protein-1 } \\ \text { AP1Luc } & \begin{array}{l}\text { luciferase reporter construct driven by multi- } \\ \text { merised AP1 consensus sequences }\end{array} \\ \text { Bc12 } & \begin{array}{l}\text { B-cell leukaemia/lymphoma 2 } \\ \text { glutathione } S \text {-transferase }\end{array} \\ \text { GST } & \text { islet brain 1 } \\ \text { IB1 } & \text { c-Jun N-terminal kinases } \\ \text { JNK } & \text { luciferase reporter construct } \\ \text { Luc } & \text { mitogen-activated protein kinase } 8 \\ \text { MAPK8 } & \text { rat insulin II promoter } \\ \text { Rip } & \text { rat insulin promoter element } \\ \text { RIPE } & \text { rip linked to the luciferase reporter } \\ \text { RipLuc } & \end{array}$




\section{Introduction}

A decline in the number of insulin-producing beta cells and/or their intrinsic ability to produce and/or secrete insulin contributes to the pathophysiology of type 2 diabetes [1]. It is now accepted that this beta cell inadequacy results in part from oxidative stress due to adverse effects of chronic elevation of glucose and free or non-esterified fatty acids [2-4]. Among the major mechanisms that have been associated with oxidative stress, is induction of the c-Jun N-terminal kinases (JNK, now known as mitogen-activated protein kinase 8 [MAPK8]) signalling pathway, leading to activation of activator protein-1 (AP1) transcriptional factors complex [5, 6]. Suppression of this pathway prevents the loss of preproinsulin gene expression and apoptosis $[7,8]$.

Islet-brain $1 / \mathrm{JNK}$-interacting protein 1 (IB1; now known as MAPK8 interacting protein 1) is a mammalian scaffold protein involved in the regulation of the JNK pathway [911]. One of the outcomes of this regulation is to prevent the activation of c-Jun (now known as JUN or Jun oncogene), a transcription factor included in the AP1 transcriptional complex that directly represses production of insulin and induces beta cell apoptosis [11-14]. Reduction in IB1 content diminishes preproinsulin mRNA levels and renders the cells more sensitive to stress-induced programmed death $[11,15,16]$. The importance of IB1 levels in beta cells has been confirmed in human diabetes. A missense mutation (S59N) in the gene encoding IB1 has been found to cosegregate with diabetes in a French family with a monogenic form of type 2 diabetes. Ex vivo, this mutation reduces the stability of IB1, leading to decreased insulin promoter activity and acceleration of the rate of cell apoptosis $[11,17]$.

Elevated levels of oxidised LDL-cholesterol, together with low HDL-cholesterol, are typical symptoms of diabetic dyslipidaemia and risk factors for prediabetic and diabetic patients to develop cardiovascular diseases [1820]. Oxidised LDL is produced in the subendothelial space and is taken up by resident macrophages via scavenger receptors [21-23], leading to their transformation into foam cells. A recent report shows that beta cells express scavenger receptor class $\mathrm{B}$, member 1 and $\mathrm{CD} 36$, two scavenger receptors for oxidised LDL, and that incubation of beta cells with oxidised LDL causes a decline in specialised tasks including insulin synthesis [24]. Oxidised LDL can induce oxidative stress in several tissues, including activation of the JNK signalling pathway and AP1 transcriptional activity [25-27]. In view of these data, we postulated that JNK signalling is implicated in the alteration of insulin production and cell survival caused by oxidised LDL.

Herein, we provide evidence that oxidised LDL, but not native LDL, exerts deleterious effects on insulin levels and beta cell survival by activating the JNK pathway. Selective inhibition of this pathway with peptide inhibitors or incubation with human HDLs countered the effects mediated by oxidised LDL.

\section{Materials and methods}

Lipoprotein preparation Blood was collected from healthy donors. Plasma LDL fractions were isolated by sequential ultracentrifugation (LDL density, 1.063) and dialysed against PBS. Samples were analysed by SDS-PAGE to assess the integrity of apolipoproteins and the purity of the different fractions. The lipoprotein preparations contained less than 0.112 units of endotoxin/ $/ \mathrm{mol}$ cholesterol as determined by the kinetic chromogenic technique (Endotell, Allschwil, Switzerland). Oxidation of LDL particles (at $1 \mathrm{mg} / \mathrm{ml}$ protein concentration in PBS) was performed by incubation with $5 \mu \mathrm{mol} / 1 \mathrm{CuSO}_{4}$ at $37^{\circ} \mathrm{C}$ for $18 \mathrm{~h}$. The oxidation reaction was stopped at $4^{\circ} \mathrm{C}$ for $30 \mathrm{~min}$ by adding $300 \mu \mathrm{mol} / \mathrm{l}$ EDTA and by thorough dialysis against PBS and subsequently against either DMEM or RPMI medium without fetal calf serum. The oxidation reaction was verified by determining the lipid peroxide content as previously described [28].

Preparation and culture of islets Rat islets were isolated from the pancreas of male Sprague-Dawley rats weighing $250-350 \mathrm{~g}$ by ductal injection of collagenase. The purification of islets was conducted as described [29]. Isolated human islets were obtained from the Cell Isolation and Transplantation Center (islets for research distribution programme) of the Geneva University Hospitals. Islets were cultured in CMRL-1066 supplemented with 10\% fetal bovine serum (Mediatech, Herndon, VA, USA) in a $5 \%$ $\mathrm{CO}_{2}$ humidified atmosphere at $37^{\circ} \mathrm{C}$.

Cell culture, transient transfection and plasmids The insulin-secreting cell lines (MIN6 and INS-1E) and rat isolated islets were maintained as previously described [30]. Transient transfection experiments were performed using a kit (Effectene Transfection Reagent kit; Qiagen, Basel, Switzerland) as reported [30]. The following plasmids were used for the transfection assays: a 600-base pair sequence of the rat insulin II promoter (Rip) cloned upstream of the firefly luciferase gene [11]; rat insulin promoter element (RIPE) ${ }_{3}$ Luc [11]; and a luciferase reporter construct (Luc) driven by multimerised AP1 consensus sequences (AP1Luc). The latter two are firefly luciferase reporter constructs corresponding to five copies of the (RIPE) ${ }_{3}$ binding site (containing the $\mathrm{E}$ elements) and to four copies of the canonical AP1-responsive elements inserted upstream of the TATA minimal promoter, respectively. Luciferase activities from the firefly and the renilla from 
the pRL-SV40 vector (Promega, Wallisellen, Switzerland) were measured using an assay system (Dual-Luciferase Reporter; Promega).

Measurement of insulin content Cells $\left(5 \times 10^{5}\right)$ were plated in 24-well dishes and cultured in the presence of vehicle, native and oxidised LDL for $72 \mathrm{~h}$. Afterwards, the cells were washed three times with a modified KRB/bicarbonateHEPES buffer $(140 \mathrm{mmol} / \mathrm{l} \mathrm{NaCl}, 3.6 \mathrm{mmol} / \mathrm{l} \mathrm{KCl}$, $0.5 \mathrm{mmol} / 1 \mathrm{NaH}_{2} \mathrm{PO}_{4}, 0.5 \mathrm{mmol} / 1 \mathrm{MgSO}_{4}, 1.5 \mathrm{mmol} / \mathrm{l}$ $\mathrm{CaCl}_{2}, 2 \mathrm{mmol} / 1 \mathrm{NaHCO}_{3}, 10 \mathrm{mmol} / 1 \mathrm{HEPES}, 0.1 \%$ bovine serum albumin) containing $2 \mathrm{mmol} / \mathrm{l}$ glucose. Insulin contents were extracted with acid/ethanol solution and measured by ELISA (Linco Research, St Charles, MO, USA) as recommended by the manufacturer's protocol.

Apoptosis assay Apoptosis was determined by scoring cells displaying pycnotic nuclei visualised with Hoechst 33342 (Invitrogen, Basel, Switzerland) [28].

Protein kinase assay The preparation of whole-cell protein extracts and the kinase assays were conducted as previously described [8]. Briefly, cell extracts were incubated for $1 \mathrm{~h}$ at room temperature with $1 \mu \mathrm{g}$ glutathione S-transferase (GST)-Jun (amino acids 1-89) and $10 \mu \mathrm{l}$ glutathioneagarose beads (Sigma-Aldrich, St-Gallen, Switzerland). After several washings, the beads were supplemented with JNK inhibitor or TAT (control) peptides for $20 \mathrm{~min}$ [8]. The JNK inhibitor peptides used were the JNK binding domain of IB1, which was coupled covalently to an N-terminal tenamino acid carrier peptide derived from the $\mathrm{HIV}_{-\mathrm{TAT}_{48-57}}$ sequence [8]. The retro-inverso D-enantiomer TAT and JNK inhibitor peptides (Auspep PLT, Melbourne, VIC, Australia) [8] were a gift from C. Bonny (S. A. Xigen, Lausanne, Switzerland). Phosphorylation of substrate proteins was examined after overnight exposition of polyacrylamide gels to autoradiography; gel quantifications were accomplished by Phosphor-Imager analysis (Molecular Imager FX; Bio-Rad Laboratories, Basel, Switzerland).

Nuclear protein extracts preparation and electromobility shift assays Nuclear protein extracts and binding reaction were conducted exactly as previously reported [30]. The primers used as labelled probe were: AP1: sense: 5'-CG CTTGATGAGTCAGCCGGAA-3' and antisense 5'-GGC TGACTCATCAAGCG-3'.

Western blotting, total RNA preparation and real-time $P C R$ For western blotting, the cell extracts were separated by SDS-PAGE and blotted on nitrocellulose membranes. The proteins were detected using specific antibodies and were visualised by chemiluminescence using horseradish peroxidase-coupled secondary antibodies. Total RNA from insulin-secreting cell lines and pancreatic islets was extracted using an RNA purification kit (Ambion, Austin, TX, USA) according to the manufacturer's protocol. Reverse transcription reactions were performed as previously described [30]. Real-time PCR assays were carried out on a real-time PCR detection system (MyiQ Single-Colour; Bio-Rad) using iQ SYBR Green Supermix (Bio-Rad), with $100 \mathrm{nmol} / \mathrm{l}$ primers, $1 \mu \mathrm{l}$ of template per $20 \mu \mathrm{l}$ of PCR and an annealing temperature of $59^{\circ} \mathrm{C}$. Melting curve analyses were performed on all PCRs to rule out non-specific amplification. Reactions were carried out in triplicate. Primer sequences for PCR were as follows: mouse and human insulin, sense 5'-TGGCTTCTTCTACACACCCA-3', antisense 5'-TCTAGTTGCAGTAGTTCTCCA-3'; mouse and human tubulin, sense 5'-GGAGGATGCTGCCAATAACT-3', antisense 5'-GGTGGTGAGGATGGAATTGT-3'; rat and mouse $I b l$, sense 5'-AGTGTCCAGCTTCCCTTGTC-3', antisense 5'-TTACTGTGGCCCTCTCCTTG-3'; human $I B 1$, sense 5'-ATCAGCCTGGAGGAGTTTGA-3', antisense 5'-AGGTCCATCTGCAGCATCTC-3'; human FOS, sense 5'-TGATACACTCCAAGCGGAGAC-3', antisense 5'-CCC AGTCTGCTGCATAGAAGG-3'; mouse ribosomal phosphoprotein P0 gene, sense 5'-ACCTCCTTCTTCCAGGCTTT-3', antisense 5'-CCACCTTGTCTCCAGTCTTT-3'; mouse Bcell leukaemia/lymphoma 2 (Bcl2), sense: $5^{\prime}$-CTCCCGATT CATTGCAAGTT-3', antisense 5'-TCTACTTCCTCCG CAATGCT-3'.

Statistical analyses Data are expressed as means \pm SEM. Unpaired two-tailed Student's $t$ test was used to compare groups.

\section{Results}

Oxidised LDL particles reduce insulin expression at the transcript level We first investigated the effects of oxidised LDL particles on insulin production. In vitro oxidisation of LDL-cholesterol particles by copper has been previously shown to generate similar changes in LDL particles to those occurring in endothelial cells, including lipid peroxidation and extensive hydrolysis of phosphatidylcholine [31]. For this reason, we chose to oxidise LDL particles by copper, as performed in many reports [24, 32, 33], in order to evaluate the effects of oxidised LDL on beta cells. Insulin contents were measured from MIN6 cells cultured with different concentrations of freshly purified oxidised LDL-cholesterol particles. The results show that oxidised LDL reduced insulin content in a dose-dependent manner, whereas native LDL did not affect insulin expression (Fig. 1a). Similar results were obtained in INS-1E cells (data not shown) and are consistent with the data of a previous study showing 
a

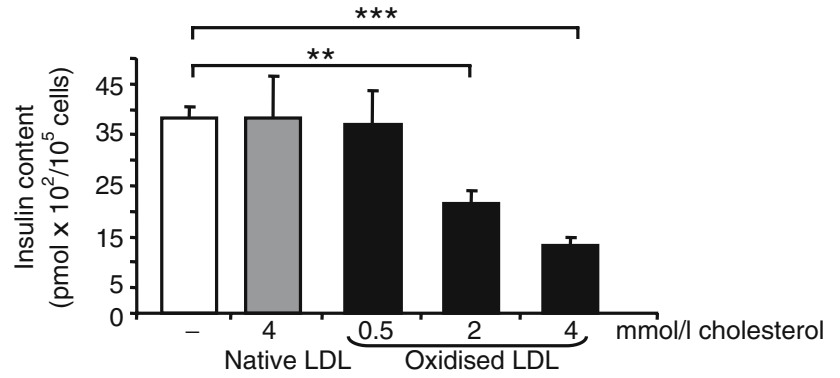

b

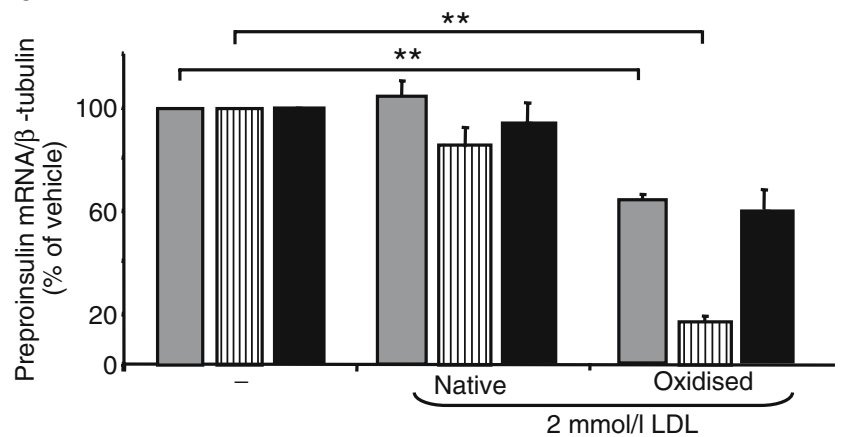

Fig. 1 Effects of oxidised LDL on insulin levels. a Insulin content of MIN6 cells exposed for $72 \mathrm{~h}$ to vehicle (-), native LDL and different concentrations of oxidised LDL-cholesterol particles. Data (mean $\pm \mathrm{SEM}$ ) are representative of four independent experiments. b Analysis of representative insulin mRNA levels by real-time PCR. Total RNA was isolated from MIN6 cells (grey bars), isolated rat islets (striped bars) and isolated human islets (black bars) that had been cultured for $72 \mathrm{~h}$ with different LDL preparations. Total RNA was then subjected to real-time PCR to measure the preproinsulin and $\beta$-tubulin (internal control) mRNA levels. Data from cells cultured with vehicle $(-)$ were set to $100 \%$. Data are the mean \pm SEM of three independent experiments. ${ }^{* *} p<0.01 ; * * * p<0.001$

that native LDL at cholesterol concentrations between 1.6 and $3.1 \mathrm{mmol} / 1$ has no effect on beta cell survival and function [28]. To evaluate the effects of modified LDL for the following experiments, we chose to incubate the cells at an oxidised LDL concentration of $2 \mathrm{mmol} / \mathrm{l}$. Under these conditions, as previously reported [24], we found that the decrease in insulin content was associated with a loss in preproinsulin mRNA levels (Fig. 1b). These oxidised LDLmediated effects also occurred at $48 \mathrm{~h}$ (data not shown) of culture and were observed in isolated human and rat islets (Fig. 1b), as well as in the insulin-secreting cell lines MIN6 (Fig. 1b) and INS-1 (data not shown).

Oxidised LDL diminishes the expression of insulin at the promoter level We next assessed the hypothesis that oxidised LDL-mediated effects on insulin expression occurs at transcriptional levels. For this purpose, a 600base pair fragment of rat insulin II promoter (Rip) linked to the luciferase reporter (RipLuc) construct was transiently transfected in INS-1E cells [11]. While culture of the transfected cells with native LDL did not significantly modify the luciferase activity of RipLuc, oxidised LDL caused a drastic decrease in production of the reporter gene (Fig. 2a). The activity of the Rip is dependent for a large part on an enhancer region ( $5^{\prime}$-GCCATCTG-3'), which is referred to as insulin control element or E element $[34,35]$. When multimerised and cloned downstream of a SV40 promoter, this region is capable of enhancing expression of a luciferase gene from the (RIPE) ${ }_{3}$ Luc construct $[11,13]$. To verify whether the E element is responsible for the loss of insulin expression, INS-1E cells transfected with this heterologous promoter construct were cultured in the presence of oxidised LDL. We found that incubation with oxidised LDL but not with native LDL generated a twofold decrease in the luciferase activity of (RIPE) ${ }_{3}$ Luc (Fig. 2b).

a

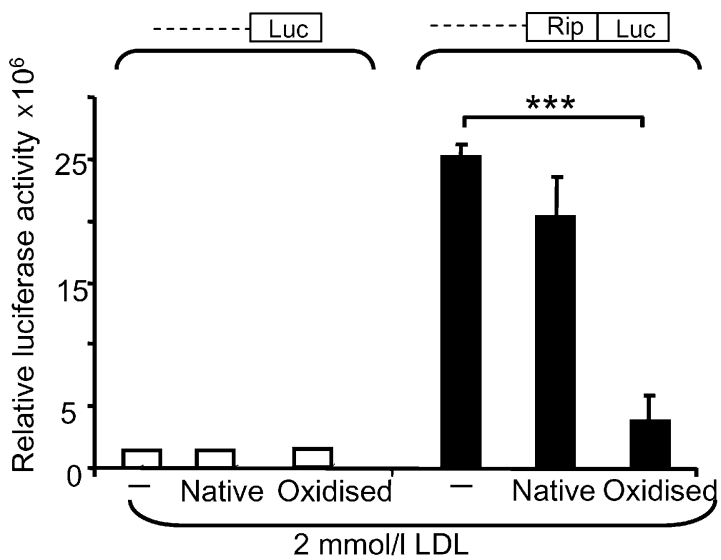

b

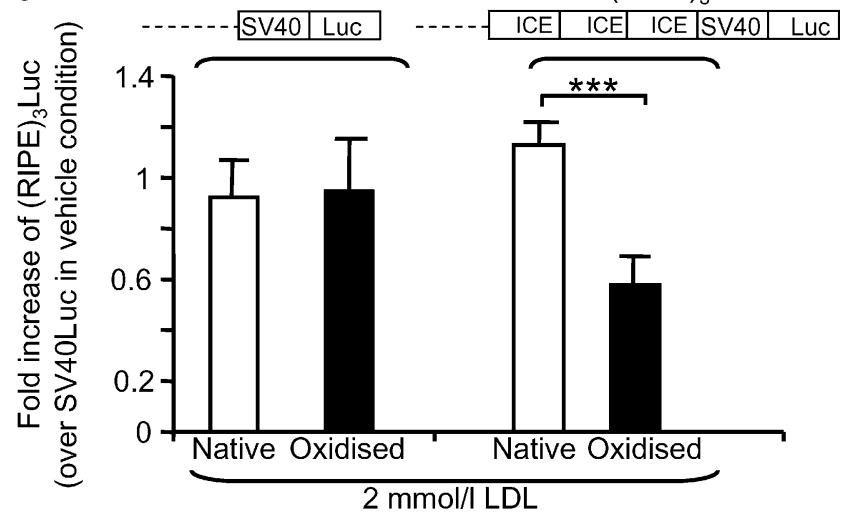

Fig. 2 Effects of oxidised LDL on insulin reporter construct activity in MIN6 cells. Vehicle (-), native and oxidised LDL-cholesterol particle preparations were added to culture medium $2 \mathrm{~h}$ after transfection. Exposure of cells to oxidised LDL led to a reduction of (a) the luciferase activity of a 600-bp fragment of the rat insulin promoter (RipLuc) and (b) the heterologous promoter activity containing insulin control element (ICE) (RIPE) ${ }_{3}$ Luc. The empty pGL3basic (Luc) and the SV40Luc vectors were used as controls for measuring the promoter activity of RipLuc and (RIPE) ${ }_{3}$ Luc, respectively. All luciferase activities were normalised using pRLSV40 renilla. Each experiment was performed at least three times in triplicate. All values are expressed as per cent of SV40Luc activity in cells cultured with vehicle $(-)$. Results are mean \pm SEM. $* * * p<0.001$ 
Introduction of a mutation in E elements [11] prevented the loss of luciferase activity mediated by oxidised LDL (data not shown). This indicates that the E element is responsible for the loss of insulin expression.

Oxidised LDL induces JNK activity, increases AP1 transcriptional activity and downregulates expression of $I b 1$ It is well documented that the E element of Rip binds the basic helix loop helix transcription factors [34, 35]. Previous reports have demonstrated that c-Jun, a component of the AP1 transcriptional complex [36], can inhibit the E47 basic helix loop helix factor, leading to inhibition of insulin promoter activity $[13,14]$. Interestingly, oxidised LDL led to oxidative stress in various cell types $[25,27]$. This phenomenon involves activation of the JNK signalling cascade and culminates in an increase in the activity of AP1 transcriptional complexes due to an elevation of c-Jun levels and its activity [25, 37, 38]. Based on these observations, we hypothesised a possible increase in AP1 activity in cells cultured with oxidised LDL. To test this assumption, we monitored AP1 activity by transiently transfecting a luciferase reporter construct driven by multimerised AP1 consensus sequences (AP1Luc). While no changes in AP1Luc activity were observed in the presence of native LDL, in cells cultured with $2 \mathrm{mmol} / \mathrm{l}$ oxidised LDL-cholesterol a twofold increase in the luciferase activity of AP1Luc was detected (Fig. 3). In addition, electromobility shift assay experiments performed using the AP1 consensus sequence as labelled probe revealed an increase in AP1 binding pattern in nuclear extracts from cells cultured with oxidised LDL (Electronic supplementary material [ESM] Fig. 1).

To determine whether the rise in AP1 activity was the result of increased JNK activity, we measured JNKmediated phosphorylation of the target transcription factor c-Jun. Total proteins from cells cultured with either $2 \mathrm{mmol} / \mathrm{l}$ of oxidised LDL or native LDL were incubated with the c-Jun recombinant. Using extracts of cells treated by oxidised LDL, kinase experiments show a timedependent increase in c-Jun phosphorylation (Fig. 4a,b).

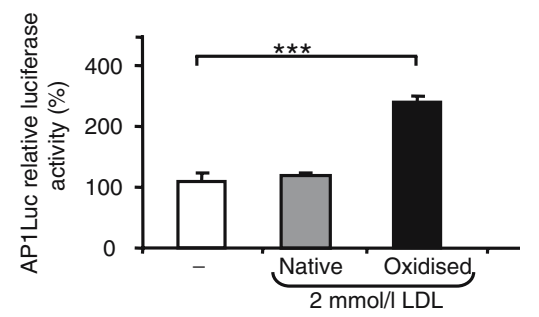

Fig. 3 Assessment of AP1 transcriptional activity in cells challenged with oxidised LDL. MIN6 cells were transiently transfected with a luciferase reporter construct driven by multimerised AP1 consensus sequences (AP1Luc). Data are expressed as per cent of control (activity of the construct in cells incubated with vehicle) and are the mean \pm SEM of three independent experiments. $* * * p<0.001$
As expected, the phosphorylation of c-Jun was efficiently blocked by $5 \mu \mathrm{mol} / 1 \mathrm{JNK}$ inhibitor peptides [8] or by the selective JNK inhibitor SP600125 (ESM Fig. 2). Phosphorylation of c-Jun occurred with extracts of cells incubated for $45 \mathrm{~min}$ and $72 \mathrm{~h}$ with oxidised LDL, whereas native LDL did not induce any change in phosphorylation of c-Jun. Phosphorylation of JNK is required for JNK to

a
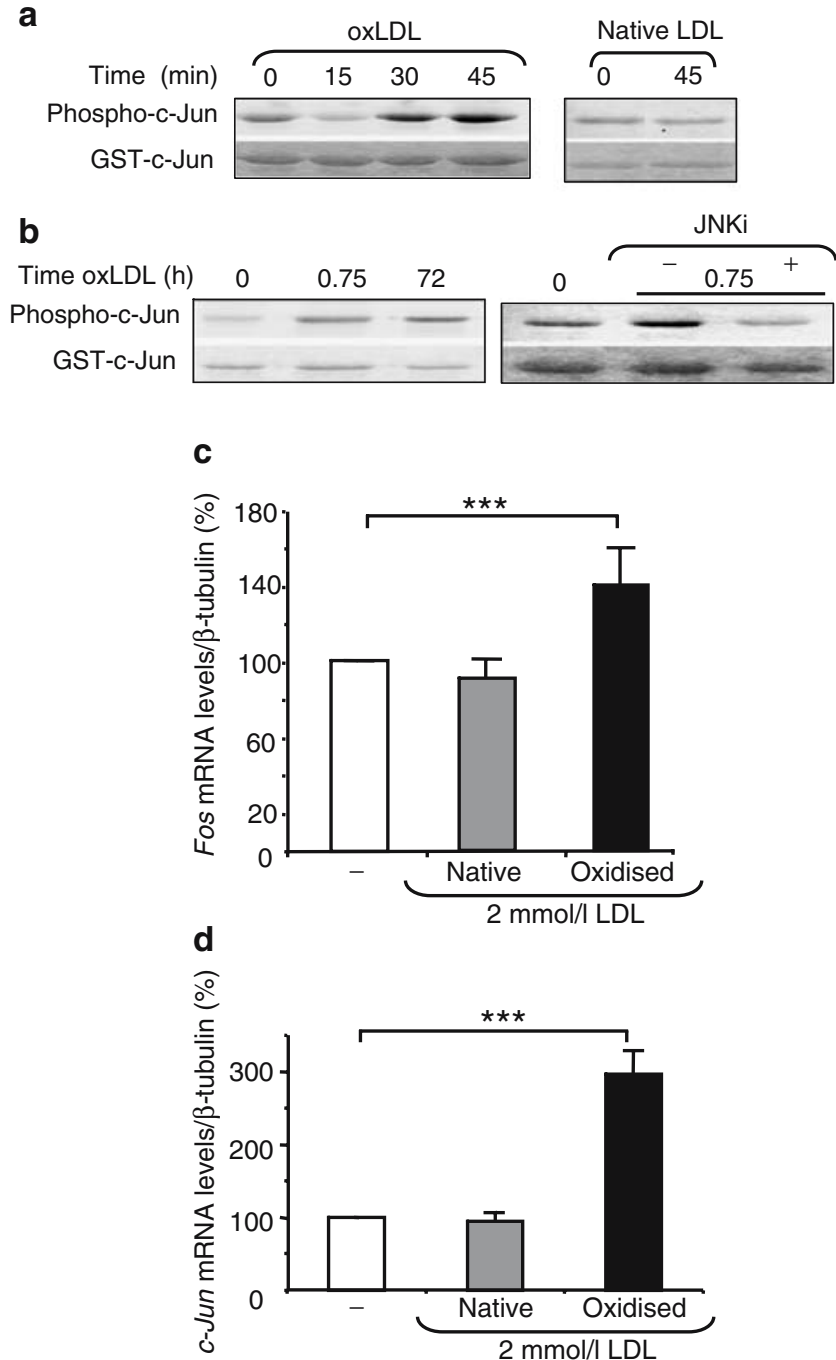

Fig. 4 Effects of oxidised LDL (oxLDL) on JNK activity. a, b Wholecell extracts were prepared from cells incubated with $2 \mathrm{mmol} / 1$ oxidised LDL or native LDL at the indicated times. JNK inhibitor peptides (JNKi) (b), at a $5 \mu \mathrm{mol} / 1$ concentration, were added in cells cultured with oxidised LDL ( $2 \mathrm{mmol} / \mathrm{l})$. JNK solid-phase JNK assays were performed with the lysates using GST-c-Jun as substrate. The reaction was loaded on a polyacrylamide gel and $\gamma-{ }^{33} \mathrm{P}-$ phosphorylation of the substrates (Phospho-c-Jun) was subsequently analysed. The gel was stained with Coomassie blue to evaluate the loading of substrate (GST-Jun). The results are representative of three independent experiments. c, d Measurement of c-Jun and Fos expression levels by realtime PCR. The mRNA levels of these genes were normalised against $\beta$-tubulin and expression levels from cells cultured with vehicle were set to $100 \%$. Data are the mean \pm SEM of four independent experiments. $* * * p<0.001$ 
phosphorylate its substrates. Consistent with this, western blotting experiments showed an increase in JNK activity in cells exposed to oxidised LDL (Fig. 4a,b). Thus, these results confirm that activation of JNK is induced by oxidised LDL. To validate activation of the JNK signalling cascade by oxidised LDL, expression of the $c$-Jun and Fos genes was then quantified. The transcriptional activity of the promoters of these two genes is positively regulated by JNK [8]. Real-time PCR analysis showed a statistically significant augmentation by 1.5 - and threefold in Fos and c-Jun mRNA levels, respectively, in MIN6 cells cultured with oxidised LDL (Fig. 4c,d).

We next investigated whether JNK activation is responsible for the loss of insulin production. Insulin-secreting cells were incubated with oxidised LDL in the presence of
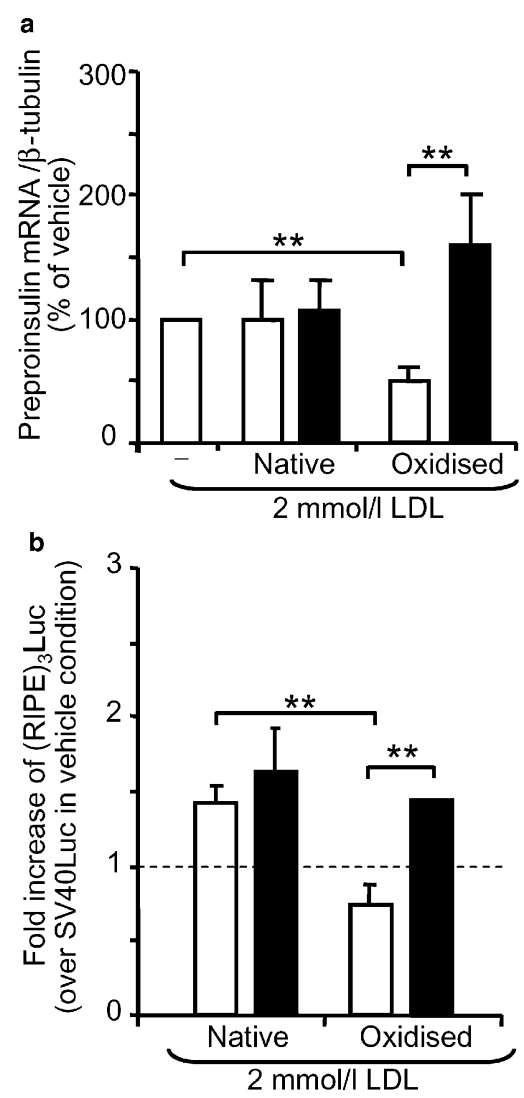

Fig. 5 Effects of JNK inhibition on the loss of insulin expression mediated by oxidised LDL. a JNK inhibitor (filled bars) or D-TAT (open bars) as control [8] was co-incubated with the different LDL preparations in MIN6 cells and preproinsulin mRNA levels were quantified by real-time PCR experiments. Data are the mean \pm SEM of four independent experiments. b Effects of JNK inhibitor on the activity of the (RIPE) $)_{3}$ Luc construct. MIN6 cells were transiently transfected with (RIPE) ${ }_{3}$ Luc and co-cultured with LDL preparations and $5 \mu \mathrm{mol} / 1$ of the JNK inhibitor (filled bars) or TAT (open bars) for $48 \mathrm{~h}$. Luciferase activities were normalised using pRLSV40 renilla. Each experiment was performed at least three times in triplicate. All values are expressed as per cent of SV40Luc activity. Results are expressed as mean \pm SEM. ${ }^{* *} p<0.01$
JNK inhibitor. Treatment of the cells with these peptides prevented the decrease in preproinsulin mRNA and (RIPE) $)_{3}$ Luc promoter activity caused by oxidised LDL (Fig. 5a,b). Prolonged exposure of cells to various stressors has been shown to activate the JNK pathway in beta cells. In some cases, this activation results from the decline of IB1 levels $[15,16,39]$. This prompted us to evaluate the expression of $I b 1$ in cells treated with the oxidised LDL preparation. Western blotting showed a decrease in IB1 protein contents in MIN6 cells treated with oxidised LDL for $72 \mathrm{~h}$, whereas the content was unaffected at $45 \mathrm{~min}$ of culture (Fig. 6a). Real-time PCR confirmed the reduction in $I B 1$ mRNA levels in isolated human and rat islets as well as in MIN6 cells cultured with oxidised LDL for $72 \mathrm{~h}$ (ESM Fig. 3).

Activation of the JNK pathway has often been associated with an increase in beta cell programmed death $[8,15,40]$. We therefore tested the viability of insulin-secreting cells in the presence of LDL-cholesterol preparations. As expected, the rate of apoptosis of the cells cultured with $2 \mathrm{mmol} / \mathrm{l}$ oxidised LDL-cholesterol for $72 \mathrm{~h}$ increased by threefold in MIN6 cells and rat isolated islets, whereas the viability of the cells incubated in the presence of native LDL was unchanged (Fig. 6b). The rate of apoptosis was similar when MIN6 cells were incubated either at 20 or at $10 \mathrm{mmol} / \mathrm{l}$ glucose. This result is in agreement with a previous report showing that glucose did not render cells more sensitive to the effects of LDL [28]. Co-treatment with JNK inhibitors prevented the apoptosis of cells mediated by oxidised LDL (Fig. 6c). Real-time PCR experiments showed a reduction of $\mathrm{Bcl} 2$ expression (Fig. 6d). This result is in agreement with the induction of the apoptotic pathway by oxidised LDL as reported in endothelial cells [41]. In contrast to early effects of oxidised LDL on insulin levels, the viability of the cells cultured with oxidised LDL for $48 \mathrm{~h}$ was apparently unchanged (data not shown). This result indicates that the loss of insulin expression induced by oxidised LDL probably precedes programmed cell death.

Taken together, our results indicate that the effects of oxidised LDL on insulin expression and beta cell survival are linked to activation of the JNK signalling pathway resulting from a decrease in IB1 contents.

$H D L$ protects cells from oxidised LDL-induced loss of insulin expression and death HDL has been described to protect beta cells from cytokine- and LDL-mediated apoptosis [28]. To assess the potential protective effects of HDL on the decline of insulin expression and the induction of cell death mediated by oxidised LDL, MIN6 cells and isolated human islets were co-incubated with HDL and LDL preparations. HDL at $1 \mathrm{mmol} / 1$ of cholesterol concentration protected the cells from apoptosis (Fig. 7a) 
a

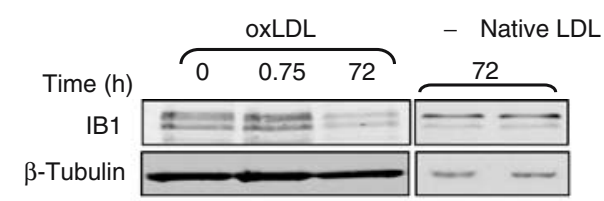

b

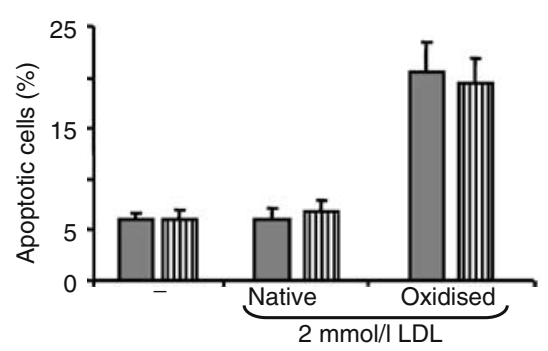

C
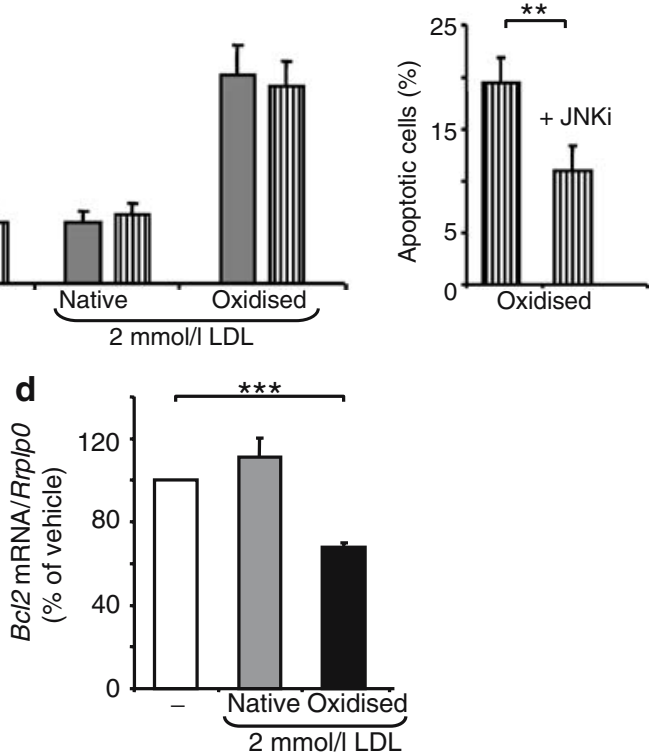

Fig. 6 Analysis of IB1 levels. a The levels of IB1 in MIN6 cells cultured at indicated times with $2 \mathrm{mmol} / \mathrm{l}$ LDL-cholesterol preparation or vehicle (-) were assessed by western blotting. The results are representative of three independent experiments. b, c The rate of apoptosis was scored in MIN6 cells (grey bars) or isolated rat islets (striped bars), co-cultured with $2 \mathrm{mmol} / \mathrm{l} \mathrm{LDL}$ preparation (oxidised or native) or vehicle (-), in the presence (c) or absence of JNK inhibitor (JNKi). Each experiment was performed three times in triplicate. Results are expressed as mean \pm SEM. ${ }^{*} p<0.01$. d Expression of $B c l 2$ was quantified by quantitative PCR. The mRNA level was normalised against the housekeeping acidic ribosomal phosphoprotein $\mathrm{P} 0$ gene $(\operatorname{Rplp} 0)$ and expression levels from cells cultured with vehicle were set to $100 \%$. Data are the mean \pm SEM of three independent experiments. $* * * p<0.001$

and prevented the reduction in $B c l 2$ expression induced by oxidised LDL (Fig. 7b). In addition, HDL treatment partially prevented the loss of preproinsulin mRNA and promoter activity (Fig. 8a,b). The protective effects of HDL on the activity of RipLuc were also observed at $48 \mathrm{~h}$ of incubation (data not shown). HDL also efficiently prevented oxidised LDL-induced AP1Luc activity (Fig. 9a) and an increase in Fos expression in MIN6 cells (Fig. 9b) and human isolated islets (Fig. 9c). The restoration of basal activity of AP1 by HDL was already observable at $48 \mathrm{~h}$ (data not shown). In line with the loss of AP1 activity, HDL countered JNK's effects on c-Jun phosphorylation (Fig. 9d) and the decline in $I B 1$ expression (Fig. 9e,f). These data suggest that HDL exerts its protective action by blocking the effects of oxidised LDL on the JNK signalling pathway.

\section{Discussion}

Several studies have reported expression of receptors for native and modified forms of LDL, including scavenger receptor class $\mathrm{B}$, member 1 and $\mathrm{CD} 36$ scavenger receptors, as well as the uptake of these lipoproteins in pancreatic beta cells [24, 28, 33, 42]. Herein, in agreement with a previous study, we found that insulin-secreting cells cultured with oxidised LDL have reduced preproinsulin gene expression [24]. This perturbed expression was observed at protein and mRNA levels, both in isolated human and rat islets and in several insulin-secreting cell lines. The reduced luciferase activity of RipLuc and the multimerised E elementscontaining promoter (RIPE) ${ }_{3}$ Luc suggests that oxidised LDL particles exert their action on the preproinsulin gene at the transcriptional levels. This effect is mediated through the $\mathrm{E}$ elements and is not the result of irreversible cell damage as can be seen from the fact that mutation of these elements prevents the changes in luciferase activity of (RIPE) $)_{3}$ Luc triggered by oxidised LDL. Several lines of evidence support a role for c-Jun, a component of the AP1 transcriptional complex, in the decline of preproinsulin gene transcription mediated by oxidised LDL [13]. Overexpression of $c$-Jun has been shown to indirectly repress the enhancer activity of the E elements by interfering with the transactivating capacity of basic helix loop helix transcription factors, which bind to the former element $[13,14]$. Conversely, induction of insulin expression is accompanied by a decrease in c-Jun expression [43]. In line with these observations, we found that the impaired preproinsulin expression is associated with an increase in AP1 transcriptional activity and c-Jun expression.

AP1 activity and c-Jun expression are induced by an unusually broad range of environmental stressors [44]. Many of these stimuli activate JNKs, leading to enhanced AP1 transcriptional activity. In cultured human fibroblasts and human aortic endothelial cells, oxidised LDL has been reported to increase the activity of AP1 and JNK, respectively [25, 26, 45]. Moreover, activation of the JNK pathway by overexpressing mitogen activated protein kinase kinase kinase 1 in insulin-secreting cells reduces the luciferase activity of (RIPE) ${ }_{3}$ Luc [11]. For this reason, we presumed that activation of JNK by oxidised LDL was responsible for augmenting AP1 activity and therefore for reducing preproinsulin gene expression. Consistent with this, inhibition of JNK with JNK inhibitors prevented the loss of (RIPE) ${ }_{3}$ Luc activity and the decrease in preproinsulin mRNA levels mediated by oxidised LDL. This finding furnishes new evidence for the possible involvement of the JNK pathway in impaired preproinsulin expression through the E element.

Increased JNK activity and c-Jun expression have been reported in many scenarios in which cells undergo 
a

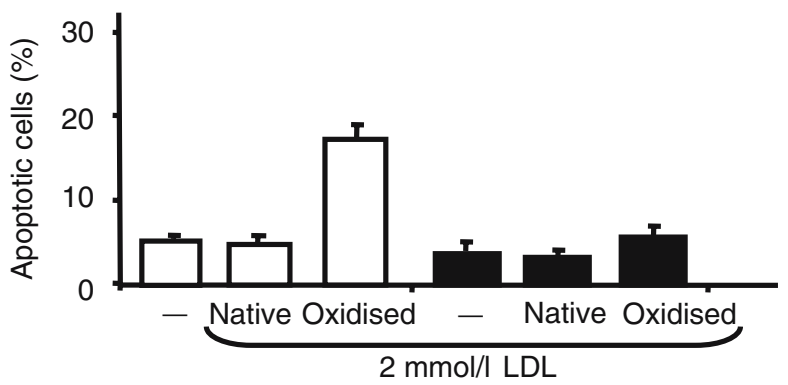

b

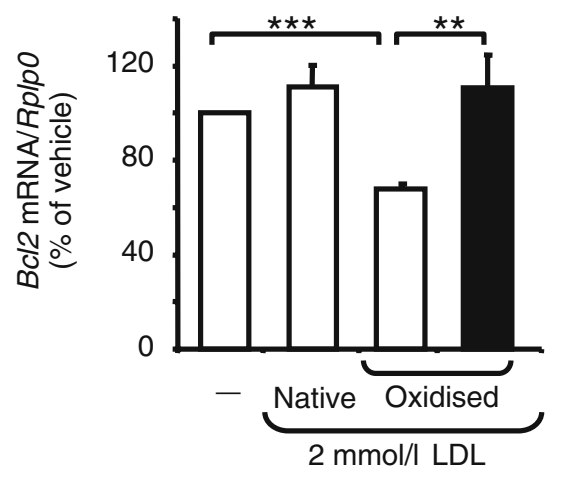

Fig. 7 Protective effects of HDL against apoptosis mediated by oxidised LDL. a Apoptosis was scored in MIN6 cells that were cocultured in the presence of different LDL preparations for $72 \mathrm{~h}$ with $1 \mathrm{mmol} / \mathrm{l} \mathrm{HDL}$-cholesterol (filled bar) or without (open bars). HDL LDL $\mathbf{b}$ The mRNA level of $B c l 2$ was quantified by real-time PCR in MIN6 cells cultured with oxidised LDL and with (filled bar) or without (open bars) $1 \mathrm{mmol} / \mathrm{l} \mathrm{HDL}$. The mRNA level was normalised against $\beta$-tubulin and the expression levels from cells cultured with vehicle were set to $100 \%$. Data are the mean \pm SEM of three independent experiments. $* * p<0.01, * * * p<0.001$

apoptosis [46, 47]. As expected, oxidised LDL induced a rise in the rate of apoptosis and JNK inhibitors protected cells against this deleterious effect. The reduction of $\mathrm{Bcl} 2$ expression confirms activation of the apoptotic pathway induced by oxidised LDL. In contrast, native LDL at $2 \mathrm{mmol} / \mathrm{l}$ cholesterol concentration did not induce apoptosis. This result is in agreement with previous studies showing that native LDL-cholesterol at concentrations lower than $3.1 \mathrm{mmol} / 1$ cholesterol does not cause apoptosis $[24,28]$. Some reports found no effects of oxidised LDL on apoptosis [24, 33]. The discrepancy between the latter studies and our data could be due to the length of exposure to oxidised LDL. Indeed, we observed that $48 \mathrm{~h}$ incubation with oxidised LDL is sufficient to initiate a slight decrease in insulin levels but not to affect the rate of apoptosis (data not shown). Thus, these data confirm that the loss of insulin levels caused by oxidised LDL is not a consequence of cell death and might precede the apoptotic events.

IB1 is a key modulator of the JNK pathway and is required for cell survival and insulin expression [11, 15]. Long-term exposure of cells to proapoptotic stimuli a
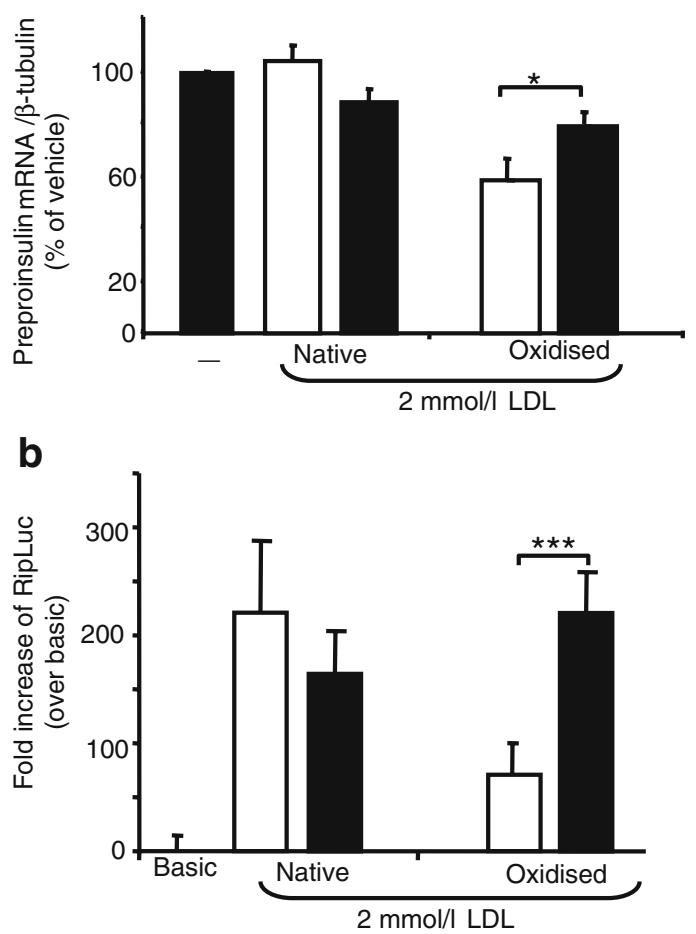

Fig. 8 Protective effects of HDL on the loss of insulin levels induced by oxidised LDL. a The preproinsulin mRNA levels were quantified by real-time PCR experiments in cells incubated for $72 \mathrm{~h}$ in the presence (filled bars) or absence (open bars) of $1 \mathrm{mmol} / \mathrm{l}$ of HDL and $2 \mathrm{mmol} / \mathrm{l}$ of LDL preparation. Results are expressed as the mean \pm SEM of at least three independent experiments measured in triplicate. * $p<0.05$. b Transient transfection experiments were performed to monitor the activity of RipLuc in cells incubated for $72 \mathrm{~h}$ in the presence (closed bars) or absence (open bars) of $1 \mathrm{mmol} / \mathrm{l}$ of HDL and $2 \mathrm{mmol} / \mathrm{l}$ of LDL preparation. Data (b) are expressed as fold increase of RipLuc over the pGL3basic vector (Basic). All results are expressed as the mean \pm SEM of at least three independent experiments measured in triplicate. ${ }^{* * *} p<0.001$

diminishes expression of $I b l[15,16]$. Such a decrease induces the JNK pathway and the subsequent activation of AP1, thereby leading to impaired insulin synthesis and increased apoptosis $[11,15,16]$. As expected, IB1 levels were reduced in cells treated with oxidised LDL for $72 \mathrm{~h}$. In contrast, these levels were unchanged after $45 \mathrm{~min}$ of treatment, although JNK activity occurred at that time point. Therefore, the data show that the early effects of oxidised LDL on induction of JNK activity do not require downregulation of IB1. However, the latter event can be responsible for maintaining prolonged activation of JNK.

In patients with diabetes and metabolic syndrome, low serum HDL levels and elevated oxidised LDL concentrations are risk factors for the the development of cardiovascular diseases [18-20]. While oxidised LDL has pro-atherogenic effects, HDL is known to be anti-athero- 
Fig. 9 HDL prevents induction of the JNK pathway mediated by oxidised LDL. a MIN6 cells were transiently transfected with the AP1Luc construct and incubated with vehicle, native and oxidised LDL with (closed bars) or without (open bars) $1 \mathrm{mmol} / 1$ HDL. b Fos mRNA levels were measured in MIN6 cells and (c) in human islets cocultured with LDL preparations and with (filled bars) or without (open bars) $1 \mathrm{mmol} / 1 \mathrm{HDL}-$ cholesterol for $72 \mathrm{~h}$. d JNK activity was measured in wholeprotein extracts from MIN6 cells cultured with vehicle $(-)$, native and oxidised LDL plus or minus $1 \mathrm{mmol} / \mathrm{l} \mathrm{HDL}$. e The effects of HDL on $I b 1$ mRNA levels were assessed in MIN6 cells and $\mathbf{f}$ in human isolated islets exposed to LDL preparations and HDL (filled bars) for $72 \mathrm{~h}$. The mRNA level was normalised against $\beta$-tubulin. Expression levels from cells cultured with native LDL were set to $100 \%$. Data in all panels are the mean \pm SEM of five independent experiments. $* p<0.05$, $* * p<0.01, * * * p<0.001$ a
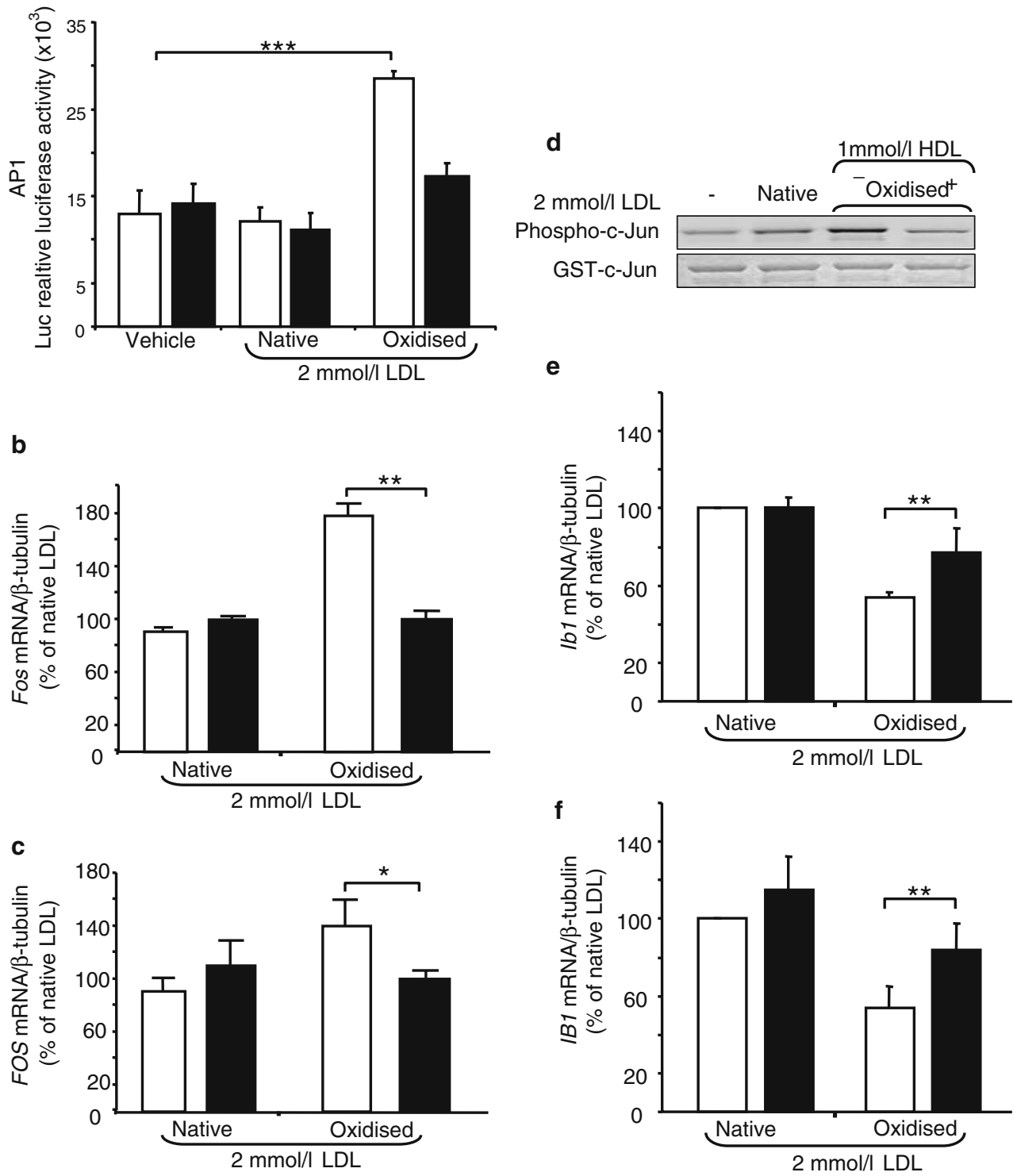

genic and cardioprotective. Besides its role in the reverse transport of cholesterol, HDL has been shown in vitro to exert its effects by inhibiting LDL oxidation and cell signalling mediated by oxidised LDL; it also counters several adverse biological effects, such as cytotoxicity and inflammatory responses triggered by oxidised LDL [19, 48, 49]. In this report, we establish that HDL efficiently counters the effects of oxidised LDL on apoptosis by restoring expression of $\mathrm{Bcl} 2$. One possible mechanism is the depletion by HDL of LDL from lipid peroxides through enzymatic hydrolysis of phospholipid hydroperoxides, a process effected by the HDL-bound enzyme paraoxonase. This has been shown to reduce cytokine production stimulated by oxidised LDL [50]. In addition, the idea that HDL mediates its action by preventing activation of the
JNK pathway is supported by the fact that JNK and AP1 activities were not induced and that IB1 and FOS levels were unaltered in cells co-cultured with oxidised LDL and HDL. This hypothesis is supported by the fact that HDL protects insulin-secreting cells from apoptosis induced by VLDL [28]. As is the case here for oxidised LDL, VLDLmediated apoptosis was linked to impaired $I b 1$ expression and an increase in JNK activity [28].

Our data also show that HDL exerted its effects on insulin levels and AP1 activity as early as the 48-h time point. At that incubation time, downregulation of $I b 1$ and apoptosis did not occur. Thus, HDL counters the oxidised LDL-mediated activation of JNK in a manner that is both dependent and independent of IB1. More than 20 proteins are associated with HDL. These include apolipoproteins that serve as 
structural components, cofactors or inhibitors of enzymes, as well as ligands of receptors. Future studies will have to clarify which of these components mediate the protective effects of HDL, which counter those of oxidised LDL, on beta cells.

Finally, this study highlights the biological consequences and the relationship between the levels of the modified lipoproteins and HDL for beta cell function. Reductions in the concentration of HDL could potentiate the effects of oxidised LDL, thereby contributing to beta cell dysfunction. Therefore, like hyperglycaemia and NEFA, modified LDL could contribute to the development of diabetes. A better understanding of the mechanisms underlying the effects of oxidised LDL and HDL will help elucidate the causes of human type 2 diabetes and may lead to novel strategies for treatment or prevention of diabetes.

Acknowledgements This work was supported by grants from the Swiss National Foundation (3100A0-105425, 310000-109281/1, 3200B0-101746 and 3100A0-107819 to A. Abderrahmani, G. Waeber, R. Regazzi and C. Widmann, respectively). We were also supported by the Young Independent Investigator grant from the Swiss Society of Endocrinology and Diabetology to A. Abderrahmani, as well as by the Placide Nicod and Octav Botnar Foundations.

Duality of interest The authors of this manuscript have no dualities of interest.

\section{References}

1. Donath MY, Ehses JA, Maedler K et al (2005) Mechanisms of beta-cell death in type 2 diabetes. Diabetes 54(Suppl 2):S108 S113

2. Kaneto H, Kawamori D, Matsuoka TA et al (2005) Oxidative stress and pancreatic beta-cell dysfunction. Am J Ther 12:529-533

3. Kajimoto Y, Kaneto H (2004) Role of oxidative stress in pancreatic beta-cell dysfunction. Ann N Y Acad Sci 1011:168-176

4. Kaneto H, Nakatani Y, Kawamori D et al (2005) Role of oxidative stress, endoplasmic reticulum stress, and c-Jun $\mathrm{N}$-terminal kinase in pancreatic beta-cell dysfunction and insulin resistance. Int $\mathrm{J}$ Biochem Cell Biol 37:1595-1608

5. Derijard B, Hibi M, Wu IH et al (1994) JNK1: a protein kinase stimulated by UV light and Ha-Ras that binds and phosphorylates the c-Jun activation domain. Cell 76:1025-1037

6. Hibi M, Lin A, Smeal T et al (1993) Identification of an oncoprotein- and UV-responsive protein kinase that binds and potentiates the c-Jun activation domain. Genes Dev 7:2135-2148

7. Kaneto H, Xu G, Fujii N et al (2002) Involvement of c-Jun Nterminal kinase in oxidative stress-mediated suppression of insulin gene expression. J Biol Chem 277:30010-30018

8. Bonny C, Oberson A, Negri S et al (2001) Cell-permeable peptide inhibitors of JNK: novel blockers of beta-cell death. Diabetes 50:77-82

9. Bonny C, Nicod P, Waeber G (1998) IB1, a JIP-1-related nuclear protein present in insulin-secreting cells. J Biol Chem 273: $1843-1846$

10. Dickens M, Rogers JS, Cavanagh J et al (1997) A cytoplasmic inhibitor of the JNK signal transduction pathway. Science 277: 693-696
11. Waeber G, Delplanque J, Bonny C et al (2000) The gene MAPK 8IP1, encoding islet-brain-1, is a candidate for type 2 diabetes. Nat Genet 24:291-295

12. Zhang S, Liu J, MacGibbon G, Dragunow M et al (2002) Increased expression and activation of c-Jun contributes to human amylin-induced apoptosis in pancreatic islet beta-cells. J Mol Biol 324:271-285

13. Henderson E, Stein R (1994) c-jun inhibits transcriptional activation by the insulin enhancer, and the insulin control element is the target of control. Mol Cell Biol 14:655-662

14. Robinson GL, Henderson E, Massari ME et al (1995) c-jun inhibits insulin control element-mediated transcription by affecting the transactivation potential of the E2A gene products. Mol Cell Biol 15:1398-1404

15. Bonny C, Oberson A, Steinmann M et al (2000) IB1 reduces cytokine-induced apoptosis of insulin-secreting cells. J Biol Chem 275:16466-16472

16. Tawadros T, Formenton A, Dudler J et al (2002) The scaffold protein IB1/JIP-1 controls the activation of JNK in rat stressed urothelium. J Cell Sci 115:385-393

17. Allaman-Pillet N, Storling J, Oberson A et al (2003) Calcium- and proteasome-dependent degradation of the JNK scaffold protein islet-brain 1. J Biol Chem 278:48720-48726

18. Cullen P, von Eckardstein A, Souris S et al (1999) Dyslipidaemia and cardiovascular risk in diabetes. Diabetes Obes Metab 1:189-198

19. Rohrer L, Hersberger M, von Eckardstein A (2004) High density lipoproteins in the intersection of diabetes mellitus, inflammation and cardiovascular disease. Curr Opin Lipidol 15:269-278

20. Taskinen MR (2003) Diabetic dyslipidaemia: from basic research to clinical practice. Diabetologia 46:733-749

21. Parthasarathy S, Wieland E, Steinberg D (1989) A role for endothelial cell lipoxygenase in the oxidative modification of low density lipoprotein. Proc Natl Acad Sci USA 86:1046-1050

22. Brown MS, Goldstein JL (1983) Lipoprotein receptors in the liver. Control signals for plasma cholesterol traffic. J Clin Invest 72 : $743-747$

23. Goldstein JL, Anderson RG, Brown MS (1979) Coated pits, coated vesicles, and receptor-mediated endocytosis. Nature 279: $679-685$

24. Okajima F, Kurihara M, Ono C et al (2005) Oxidized but not acetylated low-density lipoprotein reduces preproinsulin mRNA expression and secretion of insulin from HIT-T15 cells. Biochim Biophys Acta 1687:173-180

25. Lin SJ, Shyue SK, Liu PL et al (2004) Adenovirus-mediated overexpression of catalase attenuates oxLDL-induced apoptosis in human aortic endothelial cells via AP-1 and C-Jun N-terminal kinase/extracellular signal-regulated kinase mitogen-activated protein kinase pathways. J Mol Cell Cardiol 36:129-139

26. Maziere C, Morliere P, Santus R et al (2004) Inhibition of insulin signaling by oxidized low density lipoprotein. Protective effect of the antioxidant vitamin E. Atherosclerosis 175:23-30

27. Stocker R, Keaney JF Jr (2004) Role of oxidative modifications in atherosclerosis. Physiol Rev 84:1381-1478

28. Roehrich ME, Mooser V, Lenain V et al (2003) Insulin-secreting beta-cell dysfunction induced by human lipoproteins. J Biol Chem 278:18368-18375

29. Sutton R, Peters M, McShane $P$ et al (1986) Isolation of rat pancreatic islets by ductal injection of collagenase. Transplantation 42:689-691

30. Abderrahmani A, Cheviet S, Ferdaoussi M et al (2006) ICER induced by hyperglycemia represses the expression of genes essential for insulin exocytosis. EMBO J 25:977-986

31. Steinbrecher UP, Parthasarathy S, Leake DS et al (1984) Modification of low density lipoprotein by endothelial cells involves lipid peroxidation and degradation of low density lipoprotein phospholipids. Proc Natl Acad Sci USA 81:3883-3887 
32. Cnop M, Hannaert JC, Grupping AY et al (2002) Low density lipoprotein can cause death of islet beta-cells by its cellular uptake and oxidative modification. Endocrinology 143:3449-3453

33. Scheidegger KJ, Cenni B, Picard D et al (2000) Estradiol decreases IGF-1 and IGF-1 receptor expression in rat aortic smooth muscle cells. Mechanisms for its atheroprotective effects. J Biol Chem 275:38921-38928

34. Karlsson O, Edlund T, Moss JB et al (1987) A mutational analysis of the insulin gene transcription control region: expression in beta cells is dependent on two related sequences within the enhancer. Proc Natl Acad Sci USA 84:8819-8823

35. Whelan J, Poon D, Weil PA et al (1989) Pancreatic beta-cell-typespecific expression of the rat insulin II gene is controlled by positive and negative cellular transcriptional elements. Mol Cell Biol 9:3253-3259

36. Shaulian E, Karin M (2001) AP-1 in cell proliferation and survival. Oncogene 20:2390-2400

37. Go YM, Levonen AL, Moellering D et al (2001) Endothelial NOS-dependent activation of c-Jun $\mathrm{NH}_{(2)}$-terminal kinase by oxidized low-density lipoprotein. Am J Physiol Heart Circ Physiol 281:H2705-H2713

38. Wu ZL, Wang YC, Zhou Q et al (2003) Oxidized LDL induces transcription factor activator protein-1 in rat mesangial cells. Cell Biochem Funct 21:249-256

39. Tawadros T, Martin D, Abderrahmani A et al (2005) IB1/JIP1 controls JNK activation and increased during prostatic LNCaP cells neuroendocrine differentiation. Cell Signal 17: 929-939

40. Haefliger JA, Tawadros T, Meylan L et al (2003) The scaffold protein IB1/JIP-1 is a critical mediator of cytokineinduced apoptosis in pancreatic beta cells. J Cell Sci 116: 1463-1469
41. Chen J, Mehta JL, Haider N et al (2004) Role of caspases in OxLDL-induced apoptotic cascade in human coronary artery endothelial cells. Circ Res 94:269-270

42. Grupping AY, Cnop M, Van Schravendijk CF et al (1997) Low density lipoprotein binding and uptake by human and rat islet beta cells. Endocrinology 138:4064-4068

43. Inagaki N, Maekawa T, Sudo T et al (1992) c-Jun represses the human insulin promoter activity that depends on multiple cAMP response elements. Proc Natl Acad Sci USA 89:1045-1049

44. Whitmarsh AJ, Davis RJ (1996) Transcription factor AP-1 regulation by mitogen-activated protein kinase signal transduction pathways. J Mol Med 74:589-607

45. Dobreva I, Waeber G, Widmann C (2006) Lipoproteins and mitogen-activated protein kinase signaling: a role in atherogenesis? Curr Opin Lipidol 17:110-121

46. Ammendrup A, Maillard A, Nielsen K et al (2000) The c-Jun amino-terminal kinase pathway is preferentially activated by interleukin-1 and controls apoptosis in differentiating pancreatic beta-cells. Diabetes 49:1468-1476

47. Estus S, Zaks WJ, Freeman RS et al (1994) Altered gene expression in neurons during programmed cell death: identification of c-jun as necessary for neuronal apoptosis. J Cell Biol 127: $1717-1727$

48. Hersberger M, von Eckardstein A (2003) Low high-density lipoprotein cholesterol: physiological background, clinical importance and drug treatment. Drugs 63:1907-1945

49. Navab M, Berliner JA, Subbanagounder G et al (2001) HDL and the inflammatory response induced by LDL-derived oxidized phospholipids. Arterioscler Thromb Vasc Biol 21: 481-488

50. Durrington PN, Mackness B, Mackness MI (2001) Paraoxonase and atherosclerosis. Arterioscler Thromb Vasc Biol 21: $473-480$ 